\title{
Índices bioclimáticos e produtivos em diferentes galpões avícolas no semiárido paraibano ${ }^{1}$
}

\begin{abstract}
Herlúcio P. da Rocha², Dermeval A. Furtado ${ }^{3}$, José W. B. do N ascimento ${ }^{3}$ \& José H. V. Silva ${ }^{4}$
RESUMO

O bjetivou-se, com este trabalho, analisar os efeitos ambientais sobre o desempenho produtivo de frangos de corte comerciais, criados em dois aviários, localizados na região semiárida paraibana, em condições de verão, sendo um com cobertura de telha de cerâmica e outro coberto com telha de fibrocimento. $N$ ão houve diferença significativa entre os galpões $(P>0,05)$ para temperatura e umidade relativa do ar, índice de temperatura de globo negro e umidade, carga térmica de radiação e a velocidade do vento e os galpões proporcionaram, nos horários considerados mais quentes do dia (10 às $16 \mathrm{~h}$ ), valores médios considerados acima da zona de conforto, causando situação de desconforto para as aves, mas não influenciaram no seu desempenho produtivo. A temperatura da água nos dois galpões foi superior à recomendada, mas também não influenciou no desempenho produtivo. 0 nível de pressão sonora dentro dos aviários não causou desconforto às aves nem aos trabalhadores.
\end{abstract}

Palavras-chave: condições climáticas, pressão sonora, produtividade

\section{Bioclimatic and production parameters in different poultry houses in the semiarid region of Paraiba State}

\section{ABSTRACT}

The aim of this work was to analyse the environmental effects on the productive performance of commercial broiler chickens, raised in two poultry houses located in the semiarid region of Paraiba during the summer months, with one of them covered by a ceramic roof and the other covered with a fibrous cement roof. There was no significant difference between the poultry houses $(P>0.05)$ for temperature and relative humidity of air, index of black globe temperature and humidity, thermal load of radiation and wind speed. Poultry houses provided during the times considered hotest during the day (10 a.m. to 4 p.m.), average values considered above the comfort zone, causing an uncomfortable situation for the animals, but did not influence the productive performance. The water temperature in both poultry houses was higher than recommended, but also did not affect the productive performance. The sound level inside the poultry house did not cause discomfort to the birds or to the workers.

Key words: climatic conditions, sound pressure, productivity

\footnotetext{
${ }^{1}$ Trabalho extraído da Dissertação de Mestrado do primeiro autor

2 M.Sc. em Eng. Agrícola, 111, Apto 204, Manaíra, CEP 58038-200 João Pessoa, PB. Fone: (83) 8886-5789. E-mail: hprocha@yahoo.com.br 3 UAEA/U FCG. Av. A prígio Veloso 882, Bairro Universitário, CEP 58429-170, Campina Grande, PB. Fone: (83) 2101-2101. E-mail: dermeval@ deag.ufcg.edu.br; wallace@deag.ufcg.edu.br

${ }^{4}$ D AP/UFPB, CEP 58220-000 Bananeiras, PB. (83) 3367-1200. E-mail: jvilar@cft.ufpb.br
} 


\section{INTRODUÇÃO}

Em relação ao ambiente no interior das instalações para a produção animal, devem ser analisados, principalmente os que podem afetam a sua produção e o bem-estar, levando-se em consideração o ambiente térmico (temperatura, umidade, velocidade do vento e outros), o ambiente acústico (ruídos), o ambiente aéreo (gases, poeiras e fungos) e o ambiente social, sendo que, para melhorar a produção avícola intensiva em países tropicais, como o Brasil, precisa-se aprimorar os abrigos e, em algumas situações, modificar o manejo, para superar os efeitos prejudiciais provenientes de alguns fatores ambientais críticos (Furtado et al., 2003; Jácome et al., 2007; Vitorasso \& Pereira, 2009).

Os índices bioclimáticos no interior das instalações, como no galpão de frangos de corte, afetam, direta e indiretamente na produção, sobrevivência e no bem-estar das aves e, dentre os fatores ambientais, os fatores térmicos são aqueles que os afetam mais diretamente (Tinôco, 2001); portanto, o conforto térmico no interior das instalações avícolas é um fator muito importante, já que as condições climáticas inadequadas podem afetam negativamente a produção de frangos de corte, isto é, tanto o excesso de frio quanto de calor.

Segundo Barnwell \& Rossi (2003) temperatura ideal no interior dos aviários deve ser de $21,1^{\circ} \mathrm{C}$, umidade relativa do ar com média de $50 \%$ e velocidade do vento entre 2,29 e 2,41 $\mathrm{m} \mathrm{s}^{-1}$; entretanto Nicholson et al. (2004) recomendam que a temperatura para frangos na fase inicial esteja entre 32 a $35^{\circ} \mathrm{C}$, havendo um decréscimo a cada dois dias de $1,0^{\circ} \mathrm{C}$, e que a partir da terceira semana deve ficar entre 20 e $24^{\circ} \mathrm{C}$.

Em algumas regiões do Brasil, como é o caso da região Nordeste, muitas vezes ás instalações estão situadas em locais que podem registrar altas temperaturas ambientais, principalmente durante os meses de verão. Assim, nesta mesma região, na qual a avicultura se tem constituído em uma atividade de grande importância econômica, deve-se dar atenção especial à tipologia das instalações e ao acondicionamento térmico do ambiente (Furtado et al., 2003; 2005; Bueno \& Rossi, 2006).

De acordo com o Manual de Legislação de Segurança e Medicina do Trabalho, através da Norma Reguladora NR15,1978, Brasil (1996), o limite da salubridade para pessoas trabalhando $8 \mathrm{~h}$ semanais é de $85 \mathrm{~dB}$ de pressão sonora. Por outro lado, os limites de tolerância relacionados à exposição a picos de ruído de impacto e intensidade, segundo Brasil (1996), para uma máxima exposição diária permissível, são de $8 \mathrm{~h}$, das 4 à 7 h, de 1 a 3 h e de 7 min a 1 h são de 85,86 a 90, 91 a 100 e 102 a $115 \mathrm{~dB}$, respectivamente. Trabalhos têm demonstrado que níveis de pressão sonora acima do recomendado podem afetar a saúde, produção e o bem-estar dos animais e trabalhadores.

A avaliação do desempenho produtivo das aves em relação às condições ambientais oferecidas é realizada através de análise dos índices zootécnicos, como: consumo de ração das aves, ganho de peso total, conversão alimentar, peso vivo médio e taxa de mortalidade (Sarmento et al., 2005; Furtado et al., 2006; Carvalho et al., 2009).

Objetivou-se, com este trabalho, analisar os índices bioclimáticos (temperatura e umidade relativa do ar, índice de temperatura do globo negro e umidade, carga térmica de radiação, velocidade do vento), a temperatura da água, o ambiente acústico (ruídos) e os índices produtivos de frangos de corte (ganho de peso, ganho de peso diário, conversão alimentar, taxa de mortalidade e idade de abate) em dois galpões de frangos de corte, com diferentes tipos de cobertura.

\section{MATERIAL E MÉTODOS}

O experimento foi realizado no período de 25 de janeiro ao dia 08 de março de 2007, em galpões de granja comercial de frangos de corte, na Granja Natal, PB, localizada no município de Puxinanã, $\mathrm{PB}$, inserida na região semiárida paraibana. De acordo com a classificação climática de Koeppen, o clima da região é $\mathrm{AWi}$, caracterizado como clima tropical chuvoso (megatérmico) com média anual de precipitação em torno de $802,7 \mathrm{~mm}$, com latitude de $07^{\circ} 09^{\prime} 0,25^{\prime}$ ' Sul elongitude de $35^{\circ} 56^{\prime}$ e $42 \mathrm{~m} 68$ " Oeste e altitude de $657 \mathrm{~m}$.

Realizaram-se, para os índices ambientais, a análise de variância e o teste de Tukey, com o delineamento experimental inteiramente ao acaso (DIC); no esquema de parcelas subdivididas, tendo-se nas parcelas os galpões (GC e GA) e, quanto nas subparcelas, os 10 tempos de observação (das 8 às $17 \mathrm{~h}$ ), com seis repetições (número de semanas do experimento). Para os índices produtivos dos dois galpões foram realizados, também, a análise de variância e o teste de Tukey. As variáveis estudadas foram analisadas estatisticamente por meio do programa Assistat (Silva \& Azevedo, 2009).

O experimento foi realizado em dois galpões comerciais de frango de corte, distantes um do outro em $40 \mathrm{~m}$, orientados no sentido leste oeste, utilizando-se o total de 22.000 aves, das quais 11.500 no galpão com cobertura de telha de cerâmica (GC) e 10.500 no galpão com cobertura de telha de fibrocimento (GA), constituídos de machos e fêmeas, com idade de 1 dia no início do experimento e 42 dias no seu final. Todos os animais entraram nos galpões no mesmo dia e foram retirados, nos mesmos dias.

O galpão GC era construído em alvenaria, com comprimento de $125 \mathrm{~m}$, largura $12,5 \mathrm{~m}$, pé direito de $3,0 \mathrm{~m}$, constituindo uma área $15.562,50 \mathrm{~m}^{2}$; o piso interno e o passeio eram de solo cimento; cobertura de telha cerâmica, em duas águas, com inclinação de $20^{\circ}$ e beiral de $1,50 \mathrm{~m}$, com comedouros automáticos e bebedouros automáticos do tipo nipple. O galpão GA, em alvenaria, tinha comprimento de $100 \mathrm{~m}$, largura 10,0 m, pé direito de $3,0 \mathrm{~m}$, constituindo uma área de $10.000 \mathrm{~m}^{2}$, o piso interno de solo cimento e o passeio de solo argiloso; o telhado de telha ondulada de fibrocimento, com $6 \mathrm{~mm}$ de espessura, com comedouros manuais e bebedouros pendulares.

O sistema de ventilação mecanizado dos galpões era formado de ventiladores axiais, com diâmetro de 0,90 m e vazão nominal de $300 \mathrm{~m}^{3} \mathrm{~min}^{-1}$, posicionados transversalmente na lateral norte e sul do galpão, acionados quando a temperatura do ar ambiente era imediatamente superior a $27^{\circ} \mathrm{C}$, em que as cortinas permaneciam abertas durante o manejo.

Os manejos no interior das duas instalações eram iguais e receberam formulação de rações idênticas, de acordo com a 
idade; a cama de casca de arroz e bagaço de cana era revirada diariamente, pelos tratadores, no período noturno; utilizou-se o sistema de aquecimento a lenha nos primeiros 15 dias, no início da manhã e no início da noite, com as cortinas totalmente fechadas.

Os índices ambientais: temperatura do ar (TA), umidade relativa do ar (UR) e velocidade do vento (VV) foram coletados instantaneamente, de hora em hora, através de um termômetro digital, com sensor posicionado a $0,40 \mathrm{~m}$, o que correspondeu ao centro de massa das aves, em três pontos do aviário (início, meio e fim), fazendo-se a média desses dados em cada galpão.

Determinou-se, também a temperatura de globo negro, através de termômetros de globo negro e se instalaram termômetros no início, meio e fim do galpão, também a uma altura de $0,40 \mathrm{~m}$.

Determinaram-se, a partir dos valores obtidos para as variáveis climatológicas, a umidade relativa do ar (UR) e o índice de temperatura de globo negro e umidade (ITGU) e a carga térmica de radiação (CTR). Obteve-se o ITGU pela expressão citada por Buffington et al. (1981) e a CTR foi calculada pela expressão de (Esmay, 1969).

$$
\mathrm{ITGU}=\mathrm{T}_{\mathrm{gn}}+0,36 \mathrm{~T}_{\mathrm{d}}-330,08
$$

donde: Tgn é a temperatura do globo negro e Tdé a temperatura do ponto de orvalho, ambas expressas em $\mathrm{K}$.

\section{CTR (TRM) $)^{4}$}

sendo: CTR, dada em W m ${ }^{-2}$, a constante de Stefan-Boltzman $\left(5,67.10-8 \mathrm{~W} \mathrm{~m}^{-2} \mathrm{~K}^{-4}\right)$ e TRM a temperatura radiante média, expressa em K; a TRM é a temperatura de uma circunvizinhança, considerada uniformemente negra, para eliminar o efeito da reflexão com a qual o corpo (globo negro) troca tanto quantidade de energia quanto a do ambiente considerado (Bond et al., 1961). A TRM foi obtida pela equação.

$$
\mathrm{TRM}=100 \cdot\left[2,51 \cdot \mathrm{v}^{1 / 2}\left(\mathrm{~T}_{\mathrm{gn}}-\mathrm{T}_{\mathrm{a}}\right)+\left(\mathrm{T}_{\mathrm{gn}} / 1000\right)^{4}\right]^{1 / 4}
$$

A TRM é dada em K; v é a velocidade do vento em $\mathrm{m} \mathrm{s}^{-1}$ e Ta a temperatura ambiente, em K.

Efetuou-se a leitura da temperatura da água a cada hora, das 8 às $17 \mathrm{~h}$, em bebedouros localizados em diferentes posições nos dois galpões, utilizando-se de um termômetro infravermelho. O mesmo equipamento foi usado para coletar a temperatura superficial da cama de frangos em ambos os galpões, a uma distância de 0,50, 1,0 e 2,0 m, em diferentes posições, fazendo-se a média desses dados.

Efetuou-se a coleta dos níveis de pressão sonora durante todo o experimento, das 8 às $17 \mathrm{~h}$, a cada hora, no início, meio e fim dos galpões, a uma altura de $0,40 \mathrm{~m}$ do piso, calculando-se a média dos galpões. Para a coleta dos dados utilizou-se um equipamento de nível sonoro (decibelímetro). Os níveis foram registrados através da escala normal e da escala de pico de intensidade.

A avaliação do desempenho zootécnico das aves se deu por meio da retirada total dos lotes nos galpões, dos índices de desempenho produtivo, através do peso, ganho de peso diário, conversão alimentar e taxa de mortalidade.

\section{RESULTADOS E DISCUSSÃO}

O resumo da análise de variância para os valores de temperatura ambiente (TA), umidade relativa do ar (UR), o índice de temperatura do globo negro e umidade (ITGU), carga térmica de radiação (CTR) e a velocidade do vento (VV), nos dois sistemas de acondicionamento, horários de observação e a interação entre os sistemas e os horários, estão apresentados na Tabela 1. Nota-se que não houve efeito significativo entre os sistemas de acondicionamento $(\mathrm{S})$; quanto aos horários $(\mathrm{H})$ a diferença foi significativa $(\mathrm{P}<0,01)$; na interação dos sistemas com os horários $(\mathrm{S} \times \mathrm{H})$ houve significância $(\mathrm{P}<0,05)$ apenas na TA.

As médias dos valores TA, UR, ITGU, CTR e VV para os diferentes horários e sistemas de acondicionamento, estão apresentadas na Tabela 2, na qual se constata diferença estatística $(\mathrm{P}<0,05)$ entre os diversos horários de observação, ao longo do dia, entre os índices de conforto térmico.

Observou-se, analisando-se os sistemas GC e GA, um acréscimo na TA das 8 às $12 \mathrm{~h}$, com valores mais elevados nos horários das 11 às $15 \mathrm{~h}$, tendo seu pico de valor máximo às $12 \mathrm{~h}$. Tomando-se por base os valores citados por Nicholson et al. (2004) e Barnwell \& Rossi (2003), que citam como ideal para frangos adultos uma temperatura de 20 a $24{ }^{\circ} \mathrm{C}$, nota-se desconforto térmico para as aves em todos os horários analisados, sendo que nos horários das 12 às $15 \mathrm{~h}$ a TA esteve aproximadamente $8^{\circ} \mathrm{C}$ acima da ideal.

A cobertura dos galpões com telha de cerâmica (GC) e de fibrocimento (GA) não apresentou diferenças significativa entre eles, fato que demonstra suas utilizações no estado da Paraíba

Tabela 1. Resumo das análises de variância referente aos efeitos dos sistemas de acondicionamento ambiente (S) e de

\begin{tabular}{|c|c|c|c|c|c|c|}
\hline \multirow{2}{*}{ F.V. } & \multirow{2}{*}{ G.L. } & \multicolumn{5}{|c|}{ Quadrados médios } \\
\hline & & TA & UR & ITGU & CTR & VV \\
\hline Sistemas (S) & 1 & $0,00133^{\mathrm{ns}}$ & $0,32^{\text {ns }}$ & $0,75^{\mathrm{ns}}$ & $429,10^{\mathrm{ns}}$ & $1,49^{\text {ns }}$ \\
\hline Resíduo (a) & 10 & 44,08 & 982,05 & 67,03 & 910,60 & 59,35 \\
\hline Horário (H) & 9 & $19,21 * *$ & $476,91 * *$ & $34,69 * *$ & $2884,47^{* *}$ & $3,90 * *$ \\
\hline $\mathrm{S} \times \mathrm{H}$ & 9 & $0,75 *$ & $7,57^{\text {ns }}$ & $1,33^{\text {ns }}$ & 145,28 ns & $0,61^{\text {ns }}$ \\
\hline Resíduo (b) & 90 & 0,33 & 8,03 & 0,67 & 191,94 & 1,23 \\
\hline C.V (\%) & & 1,89 & 6,03 & 1,01 & 2,76 & 31,25 \\
\hline
\end{tabular}
horas (H ), com relação à média horária dos índices de TA, U R, ITGU, CTR, VV e interação (S x H)

* = F significativo a nível de $5 \%$ de probabilidade; ${ }^{* *}=\mathrm{F}$ significativo a nível de $1 \%$ de probabilidade; ${ }^{\text {ns }}=\mathrm{F}$ não significativo

TA - Temperatura do ar; UR - Umidade relativa do ar; ITGU - Índice de temperatura do globo negro e umidade; CTR - Carga térmica de radiação; VV - Velocidade do vento 
Tabela 2. Val ores médios dos parâmetros ambientais TA, UR, ITGU, CTR e VV, para os diferentes horários e sistemas de acondicionamento do período experimental

\begin{tabular}{|c|c|c|c|c|c|c|c|c|c|c|}
\hline \multirow{2}{*}{ Horas } & \multicolumn{2}{|c|}{ TA (ㄷ) } & \multicolumn{2}{|c|}{ UR (\%) } & \multicolumn{2}{|c|}{ ITGU } & \multicolumn{2}{|c|}{ CTR $\left(W m^{-2}\right)$} & \multicolumn{2}{|c|}{$\mathrm{VV}\left(\mathrm{m} \mathrm{s}^{-1}\right)$} \\
\hline & GC & GA & GC & GA & GC & GA & GC & GA & GC & GA \\
\hline $8 \mathrm{~h}$ & $28,1 \mathrm{e}$ & $28,1 \mathrm{~d}$ & 59,6 a & $58,2 a$ & $78,5 d$ & 78,8 ef & $479,5 \mathrm{c}$ & $470,8 d$ & $2,2 b$ & $2,7 b$ \\
\hline $9 \mathrm{~h}$ & $29,4 \mathrm{~cd}$ & $30,1 \mathrm{~cd}$ & $52,8 b$ & $50,7 \mathrm{bc}$ & $79,7 \mathrm{~cd}$ & $80,6 \mathrm{~d}$ & $492,5 \mathrm{bc}$ & 497,7 bc & $3,3 a b$ & $3,0 a b$ \\
\hline $10 \mathrm{~h}$ & $30,4 b c$ & $30,4 b c$ & $47,4 \mathrm{C}$ & 47,3 cde & 81,2 bc & $81,1 \mathrm{~cd}$ & $504,6 a b c$ & $506,8 a b$ & $3,7 a b$ & $4,3 a$ \\
\hline $11 \mathrm{~h}$ & $31,3 a b$ & $31,9 a$ & $43,8 \mathrm{~cd}$ & 42,2 ef & $82,2 a b$ & $82,9 a b$ & $511,0 a b$ & $508,6 a b$ & $3,8 a b$ & $3,7 a b$ \\
\hline $12 \mathrm{~h}$ & $32,0 \mathrm{a}$ & $31,9 a$ & $41,3 \mathrm{~d}$ & $41,0 \mathrm{f}$ & $83,5 a$ & 83,2 a & 524,8 a & $515,4 a b$ & $4,0 \mathrm{a}$ & $3,4 a b$ \\
\hline $13 \mathrm{~h}$ & $31,9 a$ & $31,9 a$ & $41,0 \mathrm{~d}$ & $40,0 \mathrm{f}$ & $83,1 \mathrm{a}$ & $83,3 a$ & $516,3 a b$ & 524,3 a & $3,5 a b$ & $4,2 a$ \\
\hline $14 \mathrm{~h}$ & 31,8 a & $31,6 a$ & $41,1 \mathrm{~d}$ & $41,1 \mathrm{f}$ & $82,9 a$ & $82,3 a b c$ & $516,0 a b$ & $502,2 a b$ & $3,5 a b$ & $3,4 a b$ \\
\hline $15 \mathrm{~h}$ & $31,4 a b$ & $30,9 a b$ & $42,2 \mathrm{~cd}$ & 44,2 def & $82,4 a b$ & $81,6 \mathrm{bcd}$ & $508,0 a b$ & $499,9 a b c$ & $4,0 \mathrm{a}$ & $4,4 a$ \\
\hline $16 \mathrm{~h}$ & $30,4 b c$ & $29,8 \mathrm{~cd}$ & $46,1 \mathrm{~cd}$ & $49,0 \mathrm{~cd}$ & 81,1 bc & 80,2 de & 498,2 bc & $493,3 \mathrm{bcd}$ & $3,7 a b$ & $4,2 \mathrm{a}$ \\
\hline $17 \mathrm{~h}$ & $29,3 d$ & $28,8 \mathrm{~d}$ & $53,9 \mathrm{~b}$ & $54,6 a b$ & $79,4 d$ & $78,5 \mathrm{f}$ & $481,0 \mathrm{C}$ & $475,2 \mathrm{~cd}$ & $2,5 b$ & $3,0 a b$ \\
\hline
\end{tabular}

As médias seguidas de pelo menos uma letra semelhante minúscula na coluna, não diferem entre si a nível de $5 \%$ de probabilidade, pelo Teste de Tukey

TA - Temperatura do ar; UR - Umidade relativa do ar; ITGU - Índice de temperatura do globo negro e umidade; CTR - Carga térmica de radiação; VV - Velocidade do vento; GC - galpão com telha de cerâmica; $\mathrm{GA}$ - galpão com fribro-cimento

(Furtado et al., 2005) e que, mesmo com a presença de ventiladores, boa distância entre eles e um bom nível tecnológico de construção, não conseguiram propiciar às aves, um dos princípios fundamentais na criação animal, que é o bem-estar, evidenciando a necessidade de se utilizar outros mecanismos de resfriamento adiabático.

Bueno \& Rossi (2006) e Furtado et al. (2006), realizando pesquisas em galpões para frangos de corte e Jácome et al. (2007) e Vitorasso \& Pereira (2009), pesquisando galões para poedeiras, também encontraram valores de temperatura ambiente superiores a $28,0^{\circ} \mathrm{C}$. Furtado et al. (2003) concluíram que na microrregião de Campina Grande, $\mathrm{PB}$, como nas diversas mesorregiões do estado da Paraíba, para os períodos diurnos, as aves estavam, a partir da terceira semana, em situação de desconforto térmico, havendo necessidade, para os meses mais quentes do ano, do emprego de mecanismos de acondicionamento ambiental.

Quanto à UR, houve diferença estatística pelo teste de Tukey $(\mathrm{P}<0,05)$ nos valores médios de UR nos diferentes horários, em que a maior UR ocorreu às $8 \mathrm{~h}(59,60 \%)$, destacando-se estatisticamente dos demais horários; a partir das 10 h a UR começou a decrescer até as $17 \mathrm{~h}$ e, em seguida, ocorreu acréscimo (Tabela 2).

Notou-se, também, que no horário das 8 e 17 h os sistemas de acondicionamento proporcionaram valores de UR considerados ideais na ZCT que, segundo as recomendações devem ficar na faixa de 50 a $60 \%$; entretanto, em relação aos outros horários, ou seja, das 9 às 16 h, os valores encontrados no interior das instalações nos dois sistemas estavam fora da faixa da ZCT; portanto, a UR no interior dos galpões GC e GA apresentou esses valores críticos ao longo do dia evidenciando a necessidade da instalação de sistemas de nebulização nos galpões, o que poderia melhorar suas condições ambientais.

Nota-se que, durante o dia, houve diferença estatística nos valores médios de ITGU nos diferentes horários de observação. $\mathrm{O}$ valor mais elevado ocorreu às $12 \mathrm{~h}(83,5)$, ressaltando-se estatisticamente dos demais horários; a partir das 9 h o ITGU começou a apresentar acréscimo e um decréscimo às 17 h, com valores críticos que causaram desconforto às aves, ao longo do dia, no interior dos sistemas.

Os valores médios de ITGU em GC e GA foram superiores aos citados por Furtado et al. (2006), que conduziram experimentos com frangos em condições de verão no Agreste paraibano e constataram que valores de ITGU superiores a 75 causam desconforto às aves acima de quinze dias de vida, sendo que a situação de estresse se agravou sempre que as aves se desenvolviam; por outro lado, Jácome et al. (2007) em experimentos realizados em galpões de postura, também encontraram, no horário das 14 h, valores de ITGU também superiores aos recomendados.

Os valores médios da CTR (Tabela 2) tiveram acréscimo a partir das $10 \mathrm{~h}$, com valor máximo as 12 e $13 \mathrm{~h}$ e decréscimo a partir das 14 h, nos sistemas GC e GA; esses altos valores ao longo do dia podem ser em decorrência da falta de área verde nas circunvizinhanças das instalações. Os valores médios da CTR apresentaram, nos dois galpões, em função dos diversos horários, diferença estatística pelo teste de Tukey $(\mathrm{P}<0,05)$, obtendo maior valor às $12 \mathrm{~h}\left(524,0 \mathrm{~W} \mathrm{~m}^{-2}\right)$, no interior dos mesmos.

Furtado et al. (2006) encontraram valores médios de CTR (das 6 as 16 h) de 491,7 e 496,3 $\mathrm{W} \mathrm{m}^{-2}$, para galpões cobertos com telha de fibrocimento e com aspersão sobre a cobertura e ventilação e nebulização, respectivamente; esses dados foram semelhantes aos encontrados nesta pesquisa, quando se obteve média desses horários de $497,7 \mathrm{~W} \mathrm{~m}^{-2}$ para o sistema GA. De acordo com Tinôco (2001), os sistemas de ventilação, nebulização e aspersão, mantêm a CTR relativamente homogênea quando comparadas com as condições externas, principalmente nos dias mais quentes salientando, desta forma, a importância da utilização dos sistemas de arrefecimento.

Os valores médios da VV (Tabela 2) tiveram diferença significativa $(\mathrm{P}<0,05)$, nos diferentes horários, observandose valores variados, sendo que na parte da manhã sua maior velocidade foi às $10 \mathrm{~h}\left(3,7 \mathrm{e} 4,3 \mathrm{~m} \mathrm{~s}^{-1}\right.$, GC e GA, respectivamente), e na parte da tarde tendo seu valor máximo às $15 \mathrm{~h}\left(4,0 \mathrm{e} 4,4, \mathrm{~m} \mathrm{~s}^{-1}\right.$, para GC e GA, respectivamente), ocorrendo um decréscimo a partir das $17 \mathrm{~h}$, quando as cortinas dos galpões foram levantadas.

Segundo Tinôco (2001) a velocidade do ar pode chegar a 2,0 a 2,5 $\mathrm{m} \mathrm{s}^{-1}$ na fase adulta em condições de calor; entretanto, Barnwell \& Rossi (2003) citam que ventos com velocidades superiores a 2,41 $\mathrm{m} \mathrm{s}^{-1}$ são prejudiciais para a criação de frangos adultos. Os valores do presente trabalho foram superiores aos relatados por Bueno \& Rossi (2006) e por Vitorasso \& Pereira (2009), sendo que os valores encontrados no presente trabalho foram devidos à utilização da ventilação mecânica, usada a 
partir do $21^{\circ}$ dia de vida das aves, durante todo o dia do experimento, juntamente com a ventilação natural da região.

Os valores médios da temperatura da água nos dois sistemas estão apresentados na Figura 1, onde se vê que as temperaturas máximas, de 30,0 e $31,0^{\circ} \mathrm{C}$, ocorreram nos horários das 11 e 12 $\mathrm{h}$, respectivamente, com decréscimo às $17 \mathrm{~h}\left(27^{\circ} \mathrm{C}\right)$. Os valores médios coletados ficaram acima da temperatura sugerida por Macari \& Furlan (2001), que recomendam que a temperatura da água não deve ser superior a $24,0{ }^{\circ} \mathrm{C}$; caso contrario, pode haver decréscimo nos índices produtivos dos animais, mas não ultrapassaram o valor máximo recomendado, que deve ser inferior a temperatura corporal das aves, que estão entre 41,2 a $42,2^{\circ} \mathrm{C}$ (Tao \& Xin, 2003). Valores elevados para a temperatura da água em aviários, com diferentes bebedouros, também foram obtidos por Klosowski et al. (2004), que entre as 12 e $16 \mathrm{~h}$, encontraram valores entre 25,1 a $31,0^{\circ} \mathrm{C}$.

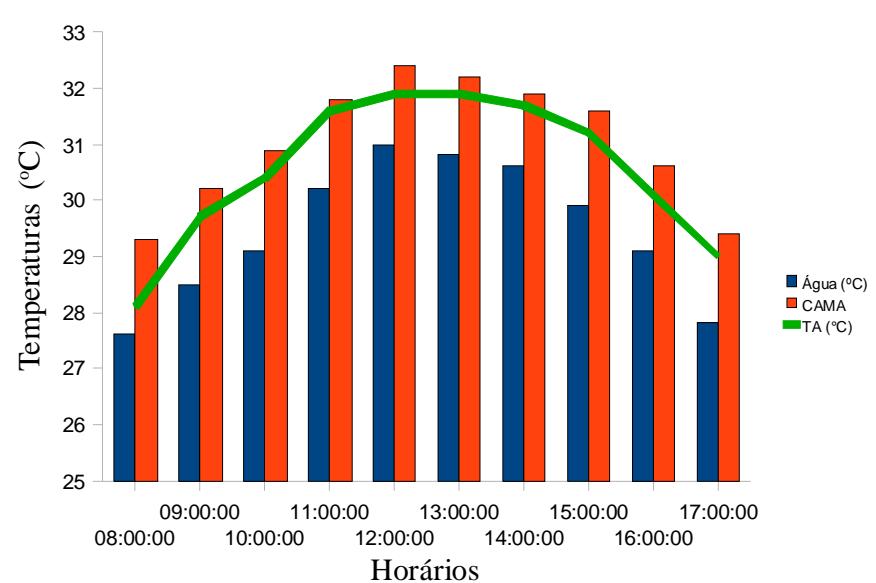

Figura 1. Relação entre a temperatura ambiente (TA), da água e da cama nos dois gal pões com telhas cerâmicas (GC) e fibrocimento (GA)

Os valores da temperatura da cama analisados não apresentaram diferença significativa $(\mathrm{P}>0,05)$ entre GC e GA, ao longo do dia e estão representados na Figura 1. A temperatura máxima ocorreu às $11\left(31^{\circ} \mathrm{C}\right)$ e $12 \mathrm{~h}\left(33,0^{\circ} \mathrm{C}\right)$, à semelhança do que se verificou com a temperatura da água. Correlacionandose a temperatura ambiente, da água e da cama (Figura 1), observa-se uma forte correlação entre referidos fatores, ou seja, à medida em que a temperatura aumenta, também aumenta a temperatura da água e da cama.

A cama tem a finalidade de proporcionar conforto as aves, diminuir o índice de lesões no peito, joelho, coxim plantar, controlar o nível de umidade, a produção de pó e amônia e prevenir a proliferação de insetos (Oliveira et al., 2003). O aumento na temperatura da água e da cama pode contribuir, juntamente com o calor gerado pelas aves e aquecedores e pelo fluxo de calor entre a instalação e o ambiente externo, para o aumento da temperatura interna, podendo propiciar desconforto térmico. Cestonaro et al. (2009) verificaram que a temperatura da cama no interior dos aviários não são uniformes e, os menores valores de temperatura de cama foram obtidos no período da manhã, com valores médios de $22^{\circ} \mathrm{C}$ e no período da tarde esses apresentaram a média de $27^{\circ} \mathrm{C}$ e, que os valores obtidos de temperatura de cama podem contribuir para elevar a temperatura do ar no interior dos aviários.
Para os níveis de pressão sonora normal (ruídos), no que se refere aos sistemas GC e GA, não houve diferença estatística $(\mathrm{P}>0,05)$ entre seus valores médios. A média dos valores do nível de pressão sonora dos galpões está apresentada na Figura 2, na qual se observa que o maior valor foi de $64,7 \mathrm{~dB}$ às $15 \mathrm{~h}$ e o menor valor, de 58,0 dB (A), às $8 \mathrm{~h}$; para os níveis de pressão sonora (picos), não houve diferença estatística ( $\mathrm{P}>$ 0,05) nos sistemas GC e GA entre seus valores médios, tendo seu maior valor de pico de 69,3 dB (A), às $15 \mathrm{~h}$. Embora apresentando este valor máximo ao longo do experimento, o mesmo está abaixo dos limites de tolerância relacionados à exposição dos trabalhadores a pico de ruído de impactos e intensidade que, segundo Brasil (1996), é de 85 dB (A), para pessoas trabalhando 8 horas semanais, não sendo necessário, portanto, o uso de protetores auriculares.

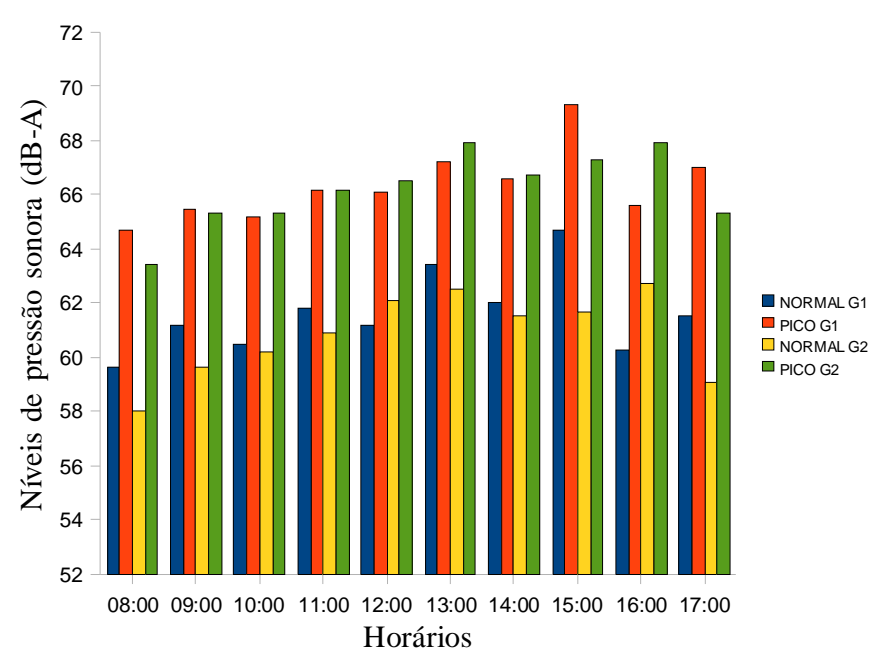

Figura 2. Valores dos níveis de pressão normal e pico em função das horas para os galpões com telhas cerâmicas (GC) e fibrocimento (GA)

Vitorasso \& Pereira (2009) pesquisando níveis de ruído em galpões de galinhas poedeiras, citam níveis de ruídos variando de 61,6 a 72, portanto abaixo dos encontrados na presente pesquisa; entretanto Trindade et al. (2006) analisando os níveis de pressão sonora em aves com diferentes idades em região semiárida brasileira, concluíram que por níveis de pressão sonora estavam em conformidade com a legislação em vigor.

Os valores médios das variáveis produtivas, peso vivo (PV), ganho de peso diário (GPD), conversão alimentar (CA), taxa de mortalidade (TM) e idade média de abate (IdAb), dos dois sistemas analisados, estão apresentados na Tabela 3, notandose que não houve diferença significativa entre os dois galpões, em nenhuma das variáveis analisadas.

Com relação ao PV, o maior valor ocorreu no sistema GC $(2,39 \mathrm{~kg})$, porém não houve diferença significativa $(\mathrm{P}>0,05) \mathrm{e}$

Tabela 3. Valores médios das variáveis produtivas PV, GPD , CA, TM e IdAb, dos dois sistemas de produção avaliados

\begin{tabular}{ccccc}
\hline Sistemas & $\begin{array}{c}\text { PV } \\
(\mathbf{k g})\end{array}$ & $\begin{array}{c}\text { GPD } \\
\mathbf{( g )}\end{array}$ & $\mathbf{C A}$ & $\begin{array}{c}\text { TM } \\
(\%)\end{array}$ \\
GC & $2,39 \mathrm{a}$ & $56,91 \mathrm{a}$ & $1,92 \mathrm{a}$ & $4,1 \mathrm{a}$ \\
GA & $2,32 \mathrm{a}$ & $55,42 \mathrm{a}$ & $1,91 \mathrm{a}$ & $4,0 \mathrm{a}$ \\
\hline
\end{tabular}

As médias seguidas de pelo menos uma letra semelhante minúscula na coluna não diferem entre si, a nível de $5 \%$ de probabilidade, pelo Teste de Tukey 
esses valores estão de abaixo dos relatados por Carvalho et al. (2009) que, aos 42 dias, encontraram valores de peso vivo superiores aos do presente trabalho $(2,75$ e $2,41 \mathrm{~kg}$ para machos e fêmea, respectivamente).

Furtado et al. (2003) encontraram valores diferentes no PV dos frangos em diferentes sistemas de acondicionamento, nos sistemas com telha de amianto com ventilação e telha de amianto com ventilação natural, de 2,67 e 2,49 kg, respectivamente, valores esses divergentes dos encontrados nesta pesquisa.

Os valores de GPD foram de 56,9 g para o sistema GC e de 55,4 g para o sistema GA; esses dados estão em conformidade com Abreu et al. (2000), que citam um GPD de 56,5 e maiores aos relatados por Sarmento et al. (2005) que, em pesquisas com frangos de corte encontraram, aos 42 dias, um GPD de 50,28 e $50,10 \mathrm{~g}$, respectivamente, e inferiores aos citados por Carvalho et al. (2009).

A CA também ficou dentro da faixa exigida pela indústria avícola de corte e semelhante às relatadas por Sarmento et al. (2005), que citam, em galpões tradicionais, conversão alimentar de 1,97 e 2,07 nos galpões climatizados, e por Furtado et al. (2006), que analisando diferentes sistemas de acondicionamento, encontraram uma CA média de 1,93. Os valores médios da TM encontrados aqui foram de $4,1 \%$ para o sistema GC e 4,0\% para o GA; Sarmento et al. (2005) obtiveram, aos 42 dias, mortalidade de 4,5\% e Furtado et al. (2006) citam uma taxa de mortalidade média de 2,8 , em trabalhos na região do Agreste paraibano e Bueno \& Rossi (2006), em trabalhos na região Sudeste, com galpões com nebulização e ventilação e ventilação tipo túnel, citam mortalidade entre 2,18 a 4,67.

De maneira geral, pode-se observar certa uniformidade nos valores encontrados para os índices produtivos, os quais estiveram dentro das faixas tidas como ideais pela indústria avícola do país. Como as aves ficaram um período do dia sob condições de estresse calórico, pode-se explicar esses índices com base em Macari \& Furlan (2001) que demonstram haver mudança comportamental das aves ao longo do dia e que, durante o dia, com o aumento da temperatura ambiente as aves entram em processo de hipertermia, com redução do apetite e, consequentemente, redução na ingestão de alimentos. À noite, as condições ambientais são mais confortáveis para os frangos já que, favorecendo os mecanismos de ingestão de alimento pelas aves, conseguem adaptar-se à situação de desconforto térmico ocorrido durante o dia, sem prejuízo drástico de suas funções produtivas.

Portanto, as aves, mesmo em um ambiente fora da sua zona de conforto térmico, conseguem ajustar-se fisiologicamente, mantendo sua homeotermia sem prejuízo de sua eficiência produtiva (Moura, 2001).

\section{ConclusõEs}

1. No interior dos galpões, independente do tipo de cobertura, a temperatura do ar, o índice de temperatura de globo negro e umidade e a carga térmica de radiação apresentaram, nos horários mais quentes, valores médios considerados acima da zona de conforto, causando situação de desconforto, porém esses parâmetros não influenciaram no desempenho produtivo das aves.

2. Nenhum dos galpões apresentou ambiente acústico (ruídos) que oferecesse insalubridade às aves e aos trabalhadores.

3. A temperatura da água nos dois galpões foi superior à recomendada, mas não influenciou no desempenho produtivo dos animais.

\section{REFERÊNCIAS BIBLIOGRÁFICAS}

Barnwell, R.; Rossi, A. Maximização da performance em períodos quentes. Avicultura Industrial, v.11, p.72-80, 2003.

Bond, T. E.; Kelly, C. F.; Garret, W. N.; Hahn, L. Evaluation of materials for livestock shades. California Agriculture, v.15, n.1, p.7-8, 1961.

Brasil. Ministério do Trabalho, Norma Reguladora NR-15, Portaria $\mathrm{n}^{\mathrm{o}} 3.214$ de 8 de Junho de 1978: Normas regulamentadoras relativas à segurança e medicina do trabalho. In: Manual de legislação de atlas de segurança e medicina do trabalho, 33.ed., São Paulo: Atlas, 1996. 523p.

Buffington, D. E.; Collasso-Arocho, A.; Canton, G. H.; Pit, D. Black globe-humidity index (BGHI) as comfort equation for dairy cows. Transactions of the ASAE, v.24, n.3, p.711-714, 1981.

Bueno, L.; Rossi, L. A. Comparação entre tecnologias de climatização para criação de frangos quanto a energia, ambiência e produtividade. Revista Brasileira de Engenharia Agrícola e Ambiental, v.10, n.2, p.497-504, 2006.

Carvalho, J. C. C.; Bertechini, A. G.; Fassani, E. J.; Rodrigues, P. B.; Pereira, R. A. N. Desempenho e características de carcaça de frangos de corte alimentados com dietas à base de milho e farelo de soja suplementadas com complexos enzimáticos. Revista Brasileira de Zootecnia, v.38, n.2, p.292-298, 2009.

Cestonaro, T.; Abreu, P. G.; Abreu, V. M. N.; Pedroso, P. D. Mapeamento da temperatura da cama na criação de aves, em diferentes sistemas de ventilação e materiais de cama. In: Simpósio Internacional sobre Gerenciamento de Resíduos de Animais, I, 2009. Anais... SIGERA, Florianópolis, Brasil, 2009.

Esmay, M. L. Principles of animal environment. 2.ed. West Port: AVI, 1969. 325p.

Furtado, D. A.; Azevedo, P. V. de; Tinôco, I. de F. F. Análise do conforto térmico em galpões avícolas com diferentes sistemas de acondicionamento. Revista Brasileira de Engenharia Agrícola e Ambiental, v.7, n.3, p.559-564, 2003.

Furtado, D. A.; Dantas, R. T.; Nascimento, J. W. B. do; Santos, J. T.; Costa, F. G. P. Efeitos de diferentes sistemas de acondicionamento ambiente sobre o desempenho de frangos de corte. Revista Brasileira de Engenharia Agrícola e Ambiental, v.10, n.2, p.484-489, 2006.

Furtado, D. A.; Tinôco, I. de F. F.; Nascimento, J. W. B. do; Leal, A. F.; Azevedo, M. A. Caracterização das instalações avícolas na mesorregião do agreste paraibano. Engenharia Agrícola, v.25, n.3, p.831-840, 2005. 
Jacome, I. M. T. D.; Furtado, D. A.; Leal, A. F.; Silva, J. H. V.; Moura, J. F. P. Avaliação de índices de conforto térmico de instalações para poedeiras no nordeste do Brasil. Revista Brasileira de Engenharia Agrícola eAmbiental, v.11, n.5, p.527531, 2007.

Klosowski, E. S.; Campos, A. T.; Gasparino, E.; Campos, A. T. de; Amaral, D. F. Temperatura da água em bebedouros utilizados em instalações par aves de postura. Engenharia Agrícola, v.24, n.3, p.493-500, 2004.

Macari, M.; Furlan, R. L. Ambiência na produção de aves em clima tropical. In: Silva, I. J. O. Ambiência na produção de aves em clima tropical. Jaboticabal: SBEA, 2001. p.31-87.

Nicholson, F. A.; Chambers, B. J.; Walker, A. W. Ammonia Emissions from broiler litter and laying hen manure management systems. Biosystems Engineering, v.89, n.2, p.175-185, 2004.

Oliveira, M. C.; Almeida, C. V.; Andrade, D. O.; Rodrigues, S. M. M. Teor de matéria seca, $\mathrm{pH}$, e amônia volatilizada da cama de frango tratada ou não com diferentes aditivos. Revista Brasileira de Zootecnia, v.32, n.4, p.951-954, 2003.

Sarmento, L. G. V.; Dantas, R. T.; Furtado, D. A.; Nascimento, J. W. B. do; Silva, J. H. V. Efeito da pintura externa do telhado sobre o ambiente climático e o desempenho de frangos de corte. Revista Agropecuária Técnica, v.26, n.2, p.152-159, 2005.
Silva, F. A. S. e; Azevedo, C. A. V. de. Principal components analysis in the software assistat-statistical assistance. In: 7th World Congress on Computers in Agriculture, 2009, Reno. Proceedings of the 7th World Congress on Computers in Agriculture. St. Joseph: ASABE, 2009. v. CD-Rom. p.1-5.

Tao, X.; Xin, H. Acute synergistic effects of air temperature, humidity, and velocity on homeostasis of market-size broilers. Transactions of the ASAE, v.46, n.2, p.491-497, 2003.

Tinôco, I. de F. F. Avicultura industrial: Novos conceitos de materiais, concepções e técnicas construtivas disponíveis para galpões avícolas brasileiros. Revista Brasileira de Ciência Avícola, v.3, n.1, p.1-30, 2001.

Trindade, J. L.; Furtado, D. A.; Nascimento, J. W. B. do; Leal, A. F. Lopes Neto, J. P. Avaliação dos níveis de pressão sonora em galinhas poedeiras no semi-árido paraibano. Revista Brasileira de Ciência Avícola, n.8, p.189, 2006.

Vitorasso, G.; Pereira, D. Análise comparativa do ambiente de aviários de postura com diferentes sistemas de acondicionamento. Revista Brasileira de Engenharia Agrícola eAmbiental, v.13, n.6, p.788-794, 2009. 